\title{
Community effects on safe water selection - the case of West Bengal
}

\author{
M. Sakamoto ${ }^{1}$, S. Mukhopadhyay ${ }^{2}$, K. Bakshi ${ }^{2} \&$ S. Roy ${ }^{2}$ \\ ${ }^{1}$ The University of Tokyo, Tokyo, Japan \\ ${ }^{2}$ Kalyani Institute for Study, Planning and Action for Rural Change (KINSPARC), Kalyani West Bengal, India
}

\begin{abstract}
Since an arsenic patient was firstly reported in 1983 in West Bengal, 35 years has been passed. Recently, pipelines using the Ganges river water have been intensively constructed in the state to provide arsenicfree drinking water in rural areas. Although development has been going on and safe water sources are more available to local people, there still exists not a small number of people who do not choose safe water sources. This study aims to investigate factors influencing their drinking water source selection. The questionnaire survey was conducted for the whole households in three villages which included one of the villages surveyed during 1983-87. Individual variables, as well as community variables, were considered in a statistical model by applying Multi-level analysis. As a result, communities had a similarity in water source selection rather than selection is made purely with individual rationality. Average community educational level had an influence rather than personal educational level.
\end{abstract}

\section{INTRODUCTION}

After an arsenic-caused patient was firstly reported in West Bengal in 1983, the following survey was conducted in 61 villages in the state from 1983 to 1987 (Saha, 1995). Recently, pipelines have been intensively constructed in West Bengal to carry water from the Ganges to rural areas for mitigating the arsenic problem. It seems that the pipeline development solves the arsenic problem in the region, however, from the recent field observations, we could say that not a small number of local people do not choose the pipeline water as their drinking water source and stick to the present water sources, namely deep tubewells or shallow tubewells that most probably contain arsenic. In 2015 , we conducted a questionnaire survey at three villages in West Bengal to know the situation and people's perceptions, including one of those villages surveyed during 1983-1987. Although our survey was conducted before the pipeline construction in the villages, it would be helpful to analyze the data to understand people's responses to arsenic risk. Hence, the aim of this study is to investigate factors influencing their decisions on choosing water sources from safe water sources or contaminated water sources, especially from viewpoints of social, cultural, and community effects on their water source selection.

\section{METHODOLOGY}

\subsection{Multi-level analysis}

The multi-level analysis is one kind of regression analysis that enables researchers to simultaneously estimate individual effects as well as group effects of an explanatory variable on a dependent variable (Hox, 2002). People are often influenced by people surrounding himself/herself when he/she makes a decision. People who belong to the same community may have similarities on their preferences, behaviors, and tendency in making decisions. In such a situation, it may be hard to do random sampling because samples from the same community may not be independent to each other on a certain attribute, and it may cause a problem in estimates of a statistical model. Therefore, we employed multi-level analysis to avoid such a bias due to community similarities. For statistical modeling, HAD ver. 16 was used.

\subsection{Community detection}

In an application of multi-level analysis, groups, where people belong, are necessary to define. Usually, administrative boundaries or affiliations, such as districts, clubs, and schools, are used. In our case, carrying water is women's role in the region, and they usually do not go far beyond their neighborhood. Moreover, water source selection is a daily activity so that the clustering to be used in the analysis should be rooted in their everyday life circles. In this study, community detection based on network analysis is employed. The procedure is as follows.

1) Geographical information of houses of interviewees is recorded and read on the software R.

2) Neighborhood contiguity is defined by a distance between houses and determined with $\mathrm{R}$ package spdep). The distance parameter is adjusted for each village by considering physical and social clustering based on the field observation.

3) Communities are extracted with $R$ package igraph. 
Table 1. Descriptive statistics.

\begin{tabular}{llcr}
\hline Village & $\begin{array}{l}\text { Sample } \\
\text { (households) }\end{array}$ & $\begin{array}{l}\text { Contaminated } \\
\text { water users }\end{array}$ & $\begin{array}{l}\text { Arsenicosis } \\
\text { patients }\end{array}$ \\
\hline A & 121 & $56(53.72 \%)$ & 20 \\
B & 135 & $3(2.22 \%)$ & 1 \\
C & 244 & $25(10.25 \%)$ & 4 \\
Total & $\mathbf{5 0 0}$ & $\mathbf{9 3 ( 1 8 . 6 0 \% )}$ & $\mathbf{2 5}$ \\
\hline
\end{tabular}

\section{RESULTS}

\subsection{Status of drinking water}

Table 1 shows the descriptive statistics from the survey at three villages. The questions were asked to all the household wives who were present during the survey. All these villages are located in Nadia district and one of these villages was surveyed during 1983-87 survey. All three villages had been identified at risk of arsenic contamination, although number of arsenic removal plants, deep tubewells, and community-size rainwater tank were installed by governmental institutes and/or NGOs. Tragically, one of these villages where arsenic was firstly reported in the region, most of installed water facilities were abandoned, and significant number of people still took water from contaminated water sources, and as a consequence there exists more arsenicosis patients than other two villages.

\subsection{Logistic regression on waters source selection}

Communities were detected by physical distance of each house. For A village, 14 communities were identified by clustering houses located within $40 \mathrm{~m}$ to each other; for B village, 7 communities were identified with $40 \mathrm{~m}$ threshold; for $\mathrm{C}$ village, 16 communities were identified with $50 \mathrm{~m}$ threshold. Logistic re-gression was applied to analyze factors influencing households' water source selection. A categorical variable is used as a dependent variable, which represents if a household uses a safe water source (deep tubewell, filtered shallow tubewell, or bottle water) or an arsenic contaminated water source (non-filtered shallow tubewell). Table 2 shows the results.

Model A includes four categorical explanatory variables. Availability means if a safe water source is available to a household or not. The sign is positive and significant. Therefore, if a water source is available to a household, the household is more likely to choose the safe water source. Hindu means if a household is Hindu or Muslim. The sign is negative and it is significant. Therefore, if a household is Hindu, the family is less likely to choose a safe water source than Muslim family. The variables regarding education were not significant. Therefore, educational experiences may not influence risk perception on arsenic. Random intercept was significant. This means that there is a similarity within communities in water source selection.

Model B includes three explanatory group variables in addition to the categorical variable Availability. Ratio of Hindu is negatively significant. It means that
Table 2. Results of multi-level logistic regression.

\begin{tabular}{lrl}
\hline Model A & Estimate & SE \\
\hline Fixed parameters & & \\
$\quad$ Intercept & 0.710 & $0.040^{* *}$ \\
Availability & 0.318 & $0.063^{* *}$ \\
Hindu $^{\mathrm{a}}$ & -0.092 & $0.04^{*}$ \\
Under secondary school $^{\mathrm{b}}$ & 0.008 & 0.031 \\
Upper secondary school $^{\mathrm{b}}$ & 0.052 & 0.034 \\
Random parameter & & \\
$\quad$ Intercept & 0.275 & $0.075^{* *}$ \\
\hline
\end{tabular}

Reference of categorical variables: ${ }^{\mathrm{a}}$ Muslim ${ }^{\mathrm{b}}$ No education. ${ }^{* *} \mathrm{p}<0.01,{ }^{*} \mathrm{p}<0.05 \quad$ Adjust R2: 0.054

Model B

Estimate

SE

\begin{tabular}{lrl} 
Fixed parameters & & \\
Intercept & 0.801 & $0.027^{* *}$ \\
Availability & 0.319 & $0.062^{* *}$ \\
Ratio of Hindu & -0.225 & $0.041^{* *}$ \\
Ratio of upper secondary school & 0.178 & $0.086^{*}$ \\
Ratio of under secondary school & -0.081 & 0.097 \\
Random parameter & & \\
$\quad$ Intercept & 0.268 & $0.072^{\text {** }}$ \\
\hline
\end{tabular}

${ }^{* *} \mathrm{p}<0.01,{ }^{*} \mathrm{p}<0.05 \quad$ Adjust R2: 0.108

if the ratio of Hindu in the community where a household belongs increases, the household is less likely to choose a safe water source. Ratio of upper secondary school is positively significant. Therefore, if there exist more people who have higher education in a community where a household belongs, the household is more likely to choose a safe water source.

\section{DISCUSSION AND CONCLUSIONS}

It has been recognized that higher education enhances better risk perception. However, the result shows that community-level education had a significant influence on water source selection rather than individual-level education. Highly educated people are often wealthy, and therefore they tend to have more accessibility to safe water sources than less educated people. The variable availability may have controlled this kind of effect of education on water source selection. Therefore, if people have more chances to talk with highly educated people beyond communities, it would encourage people to choose safe water sources. The influence of the religion is not certain at the moment. More detailed filed work would be necessary.

\section{REFERENCES}

Hox, J.J., Moerbeek, M. \& Schoot, R. 2002. Multilevel Analysis: Techniques and Applications. Routledge Academic.

Saha, K. 1995. Chronic arsenical dermatoses from tube-well water in West Bengal during 1983-87. Indian J. Dermatol. 40(1): 1-12. 